\title{
INGREDIENTES ÉTICOS EN LA EDUCACIÓN SOCIAL EL RESPETO COMO MANDATO DE SUS PROFESIONALES
}

\author{
ETHICAL INGREDIENTS IN SOCIAL EDUCATION \\ RESPECT AS A MANDATE FOR ITS PROFESSIONALS
}

\begin{abstract}
$\overline{\text { Carolina Borges Veloso }{ }^{a} \text { y Xosé Manuel Cid Fernández }{ }^{a *}}$
\end{abstract}
Fechas de recepción y aceptación: 1 de julio de 2021 y 22 de octubre de 2021

DOI: https://doi.org/10.46583/edetania_2021.60.927

\begin{abstract}
Resumen: La ética, como disciplina filosófica transversal, afecta a toda actividad humana, pero cobra mucho más protagonismo en el caso de las profesiones educativas como la educación social, a la que habitualmente se le encomienda la implementación de las políticas sociales y la atención de colectivos vulnerables. Por medio de una metodología de estudio cualitativo, pretendemos situar las coordenadas de la ética en la educación social. Primero abordaremos las cuestiones éticas inherentes a la profesión: la formación y el peso de la ética en la identidad profesional; la incidencia de los aspectos antropológicos de los agentes en la praxis; y la consideración de los instrumentos profesionales existentes para materializar estos principios éticos. Posteriormente, analizaremos los elementos externos, como la pluralidad de objetivos que interpelan a la educación social. Por último, apostaremos por el cultivo de la ética de las virtudes profesionales como forma de materializar los principios éticos, concretándolo en el valor del respeto como mandato de sus profesionales y cómo articularlo en una relación de dependencia. La ética profesional es un marco en el que asentar la profesión, como medio para alcanzar la excelencia profesional y como forma de legitimación social de su actividad. Hay que orientar la acción profesional hacia sus fines legítimos y que el agente se comprometa en el ejercicio de su profesión como un compromiso de ciudadanía, llevándola a cabo mediante el

${ }^{a}$ Facultad de Educación. Universidad de Vigo.

${ }^{*}$ Correspondencia: Universidad de Vigo. Facultad de Educación. Edificio de Facultades. As Lagoas, s/n. 32004 Ourense. España.

E-mail: xcid@uvigo.es
\end{abstract}


cultivo de las virtudes por medio de la formación y la socialización profesionales, ayudándose de los instrumentos elaborados para y desde la profesión.

Palabras clave: educación social, ética profesional, código deontológico, respeto, excelencia profesional.

Abstract: Ethics as transverse philosophy especially affect educational professions such as Social Education that implement social policies and care for vulnerable social groups. Professional ethics are not an aesthetic adornment to the profession, but its basis, its identity and its purpose to achieving professional excellence. By reviewing the relevant literature, we determine ethics in Social Education. Firstly, we address ethical issues in the professional identity. Secondly, we analyze external elements like the plurality of objectives that challenge Social Education. Lastly, we identify ethics of professional virtues as a way of materializing ethical principles. Professional action must be oriented towards its legitimate purpose and the cultivation of virtues through training and professional socialization, with the help of the instruments made for and from the profession.

Keywords: social education, professional ethics, deontological code, respect, professional excellence.

\section{INTRODUCCIÓN. ÉTICA APLICADA A LA EDUCACIÓN SOCIAL}

Junto con el progreso ya sabido de ciencias y técnicas, otra de las grandes invenciones de la Modernidad: la Ética, el discurso capaz de validar la innovación moral, el cambio de valores, normas y costumbres heredadas.

Ética para un mundo global

Amelia Valcárcel

La ética es una forma de reflexión sobre nuestras acciones, una disciplina filosófica transversal que afecta a toda actividad humana, con lo cual, el ámbito de las profesiones no puede serle ajeno. La ética cobra mucho más protagonismo, si cabe, en el caso de las profesiones educativas como la educación social, a la que se le encomienda la materialización de las políticas sociales y la atención de colectivos vulnerables. Por lo tanto, se hace imprescindible que exista un componente ético tanto en su identidad profesional como en sus actividades.

La acción profesional en educación social tiene, pues, tres dimensiones igual de importantes: la científica, la técnica y la valorativa (Vilar, 2013, p. 28), por lo que la ética profesional no debe considerarse como un añadido o un adorno 
estético, sino que se trata de un marco en el que se asienta la profesión, su identidad y sus fines.

La subjetividad posmodernista, que relativiza valores y anula la posibilidad de establecer principios éticos universales (Valcárcel, 2002), pone de máxima actualidad el debate ético sobre cómo alcanzar la justicia social, no como algo subjetivo y particular, sino como un acuerdo intersubjetivo (Cortina, 1993 p. 113).

Por medio de una metodología de estudio cualitativo, basada principalmente en el análisis de contenido mediante la revisión de literatura especializada, pretendemos situar las coordenadas de la ética en la educación social; indagar en torno a los aspectos formativos, antropológicos y psicológicos de sus profesionales, destacando la importancia de la dimensión valorativa frente a otras posturas ideológicas afiliadas excesivamente a paradigmas tecnológicos, psicologistas y burocráticos, con el fin de contribuir a materializar la ética profesional en las situaciones de conflicto más habituales por medio del cultivo de las virtudes profesionales, como el respeto por los sujetos.

En cuanto a los dilemas éticos que habitualmente afectan a la educación social, Vilar (2013, pp. 117-118) ha realizado una valiosa categorización de los ejes temáticos en conflicto: la oposición entre el encargo y la responsabilidad socialmente adquirida; la ausencia de transformación social o efectos indeseados; la precariedad, la falta de medios y omisiones en la implicación profesional; las tensiones en la relación educativa, como la asimetría o el abuso de poder; y, por último, las tensiones entre los profesionales.

El quid de la cuestión es cómo conseguir que cualquier profesional concienciado y comprometido pueda adaptar en su trabajo unos principios éticos aplicables compartidos.

La filosofía moral y la ética trabajan con teorías o conceptos universales, y por lo tanto muy generales. En este sentido, los profesores Sáez y García (2006, pp. 347-348) consideran que no es lo más apropiado apoyarse en planteamientos morales esencialistas y absolutos que se pretendan capaces de orientar y hacer actuar a cualquier tipo de profesional y a todos de la misma forma, y recomiendan e invitan a reflexionar sobre la construcción de un marco ético particular respecto a las contingencias de la profesión de educador y educadora social y a lo específico de la relación educativa, sin que esto sea óbice para inscribirla en marcos y principios éticos más generales, como la Declaración 
Universal de Derechos Humanos o los valores de la democracia. Otros marcos podrían ser las virtudes cardinales, la teoría feminista o la ética cívica.

No se refiere en ningún caso a crear una ética particular para la profesión, ya que sería un sinsentido. Como señala Amorós (1991, p. 107): "el destinatario de una ética no puede ser sino la especie humana en cuanto comunidad de seres racionales". Se trata, pues, de enfocar la praxis y la realidad laboral de los y las educadoras sociales, ofreciendo recursos y mecanismos para que puedan hacerla factible y asequible. Por lo tanto, es necesario construir un sistema de apoyo para el profesional que haga de vínculo entre la ética general y la posibilidad real de emplearla en su práctica diaria (Vilar, 2009, 2013).

\section{2. ¿ES LA EDUCACIÓN SOCIAL UNA PROFESIÓN MÁS ÉTICA QUE TÉCNICA?}

Partimos de que el componente ético tiene un gran peso en la configuración de su identidad profesional. Si bien es cierto que las buenas intenciones no garantizan una buena acción profesional y requieren de conocimientos técnicos, la situación contraria parece inverosímil: ¿técnica sin ética? Situación que haría posible el relevo del profesional por la informática o la inteligencia artificial. Por lo tanto, no ha lugar a realizar una separación tan radical, porque es una falsa dicotomía: una buena ética favorece una buena praxis, porque puede servir como marco interpretativo para orientar y guiar las acciones.

Sin embargo, hoy en día los sistemas educativos se ven afectados, por un lado, por la incertidumbre, el relativismo y el vacío posmoderno, y por otro por la pérdida de legitimidad de los valores ilustrados de la modernidad y la consiguiente decepción ante los resultados alcanzados. Este vacío está siendo cubierto por objetivos espurios, cambiando así las fuentes de las que abastecerse y horizontes a los que orientarse: se están enfocando como instrumento al servicio de la economía global, supeditando la formación integral de los estudiantes a su posible empleabilidad en el mercado laboral, tema que se ve reflejado en el efervescente debate en torno al tema de las competencias (Núñez, 2003; Cortina, 2013); pasando de la filosofía, de la ética y de la política a la economía (Pérez, 2000, p. 130; Laval, 2005), y de la pedagogía a la psicología y al omnipresente discurso emocional disfrazado de humanismo 
pero de corazón neoliberal (Cabanas y González, 2021; Prieto, 2018; Solé y Moyano, 2017; Ecclestone, 2004).

Incluso las posturas más optimistas al respecto (Caride, Sanjurjo y Trillo, 2017, p. 94), que consideran que ser competentes para el mercado y para las personas deberían ser objetivos conciliables y complementarios, admiten que, en la práctica, las universidades en muchas ocasiones están supeditando la planificación de las titulaciones a las ocupaciones definidas por el mercado laboral.

Si bien es cierto que la Universidad tiene que orientar la formación a la preparación de futuros profesionales y no organizarse en torno a la lógica disciplinar (Sáez y Molina, 2006), no todas las propuestas que vienen del mundo laboral son deseables, y la de formar operadores (Núñez, 2010) o ejecutores (Sáez, 1994) que apliquen mecánicamente programas y/o actividades, sin reflexionar sobre los motivos ni las consecuencias de sus acciones, es uno de los aspectos negativos.

Por ello, y muy especialmente en el caso de la educación obligatoria, no debe orientarse unilateralmente a las necesidades del mercado laboral, sino que el alumnado debe recibir una educación integral que le permita desenvolverse críticamente en la sociedad, hecho que no debe suponer ningún obstáculo para desarrollarse laboralmente.

Los conocimientos son, en términos de Bourdieu (2006), el capital cultural que la gente posee para desarrollarse en el mundo. Los usos de este capital cultural, según Parrenoud (2008, p. 54), son dos. El uso en el que estamos más socializados es cuando el capital cultural solo es eficaz en la medida en que este sea reconocido por terceros. Por ejemplo, la acumulación de saberes, reconocidos a través de acreditaciones, sirven a las personas para negociar un determinado puesto de trabajo, un salario, una formación, etc. El segundo uso se da cuando las personas movilizan su capital cultural para una acción concreta sin mediación del juicio de los demás. Es lo que él llama la lucha por la vida. Este segundo uso no puede olvidarse, porque constituye lo que somos como personas, más allá del mercado laboral. Las personas no podemos limitar nuestro poder ser a las actividades laborales que realizamos, porque además de personas trabajadoras SOMOS ciudadanía (entre otras cosas) y, como señala Valcárcel (2002, p. 76), para mantener nuestra ciudadanía, la igualdad y la mejor versión de nuestras democracias necesitamos una enorme capacidad de reflexión y crítica, y eso trasciende al mercado laboral. 
Pero, volviendo al campo de las profesiones, estas también precisan imperiosamente de la ética. El proceso de secularización que trajo la modernidad relevó las motivaciones religiosas que la vinculaban con el compromiso profesional para sustituirlo por el sentido de servicio competente con la sociedad (Martínez, 2006, p. 125). Las profesiones configuran y estructuran las sociedades occidentales, por lo que el reto está en ser un excelente profesional para ser un buen ciudadano, y ser un excelente ciudadano para ser un excelente profesional (Martínez, 2006, p. 139). Por ello, en la formación profesional, no se debería formar en criterios exclusivamente técnicos. Cortina (2013, p. 101) manifiesta el deber de "ser profesionales y no solo técnicos" y señala una pertinente diferencia entre técnica y práctica en términos aristotélicos. A saber: las actividades técnicas son aquellas acciones instrumentales que solo se valoran en función del fin que producen, y las actividades prácticas son aquellas que constituyen un fin en sí mismas. No es lo mismo dominar los conocimientos técnicos necesarios para transformar una planta en medicamento que en veneno. Lo que Cortina destaca es que, en el caso concreto de la educación, es un gran error formar solo a técnicos que persigan los más diversos fines, sino que es una finalidad de la educación discernir cuáles son los mejores fines, porque las técnicas cobran valor y sentido por los fines que se persiguen (p. 105).

En el caso concreto de la titulación en Educación Social, a menudo se evoca el carácter práctico de la profesión como coartada y, siendo cierta la necesidad de que la titulación forme a profesionales capaces, esta justa demanda no puede desembocar en una formación esencialmente técnica, porque la educación social pierde su razón de ser si no se enfoca a fines que sean legítimos. El ser profesionales preconizado por Cortina equivale al profesional reflexivo $y$ crítico consigo mismo y con la sociedad como ideal de la educación social de Sáez (1994). Sin embargo, adolece de una tradición actuadora-aplicacionista muy presente, resultado de su rápida evolución desde lógicas actuadoras de control y caridad, con repercusiones inmediatas en el abordaje de las cuestiones morales (Vilar, 2013, p. 142).

Como señala Núñez (1999), reflexionando en torno al tema de la formación universitaria en educación social, esta no puede pecar de ser excesivamente técnica e instrumental, porque perjudica también a los sujetos de la acción y, por extensión, a la sociedad: "Esto significa condenarlos al activismo; a la imposibilidad de la necesaria reflexión pedagógica; (...) Pero, sobre todo, 
significa que los sujetos que serán atendidos por tales educadores quedarán sometidos, ellos también, a la exclusión" (p. 20).

Por lo tanto, una buena educación, tanto profesional como cívica, precisa de la reflexión y de la formación cultural además del conocimiento técnico.

\section{3. ¿QuÉ HAY DE ÉTICA EN LOS CÓDIGOS DEONTOLÓGICOS DE LA PROFESIÓN?}

Si, como decíamos, la ética es una reflexión sobre los actos humanos en torno a sí responden al obrar bien o al obrar mal que se enuncian en principios universales, por su parte, la ética profesional pretende añadir aquellas dimensiones que se presentan y que afectan directamente al ámbito de las profesiones.

En el caso concreto de la deontología, como ciencia de los deberes, consiste en señalar las obligaciones de los profesionales, plasmándolas por escrito en documentos de valor oficial para la profesión: los códigos deontológicos (Pantoja, 2012).

Para Pantoja (2012, pp. 71-72), los códigos deontológicos tienen asociadas múltiples ventajas, como delimitar los ámbitos y responsabilidades de la profesión, aclarar su ethos y ser un indicador de profesionalidad porque eleva el grado de percepción de calidad en los servicios. Pero no están exentos de riesgos, como alimentar el corporativismo si solo defienden los intereses del grupo, coartar el debate cuando se pretende que se adopten ortodoxamente las normas prescritas por instancias superiores o que sean un elemento decorativo cuando no se exige su aplicación o se desconocen en el ámbito profesional (Pantoja, 2012).

Los profesionales de la educación social cuentan con un código deontológico desde 2007, presentado oficialmente en el V Congreso Estatal. En estos documentos se visualizan claramente los marcos éticos en los que la profesión se apoya y constituye una buena base sobre la que seguir reflexionando, teniendo en cuenta la juventud de la profesión y la dificultad que conlleva realizar una tarea de síntesis y consenso de este calado.

Siguiendo las recomendaciones del profesor Pantoja (2012, p. 78), se hace imprescindible difundir el código deontológico entre los profesionales en activo y en la formación universitaria para que no se convierta en letra muerta. De esta forma, devendrá en un documento vivo, sometido al examen de la práctica 
y a las vicisitudes profesionales, que fruto de la experiencia y de la reflexión podrá ser mejorado. Por lo tanto, la posición que defendemos ante el debate de la obligatoriedad o no del código deontológico (Vilar, 2009), y ante la posición ambigua de la asociación estatal y del colegio general, es que, para poder perfeccionarlo, debe exigirse su cumplimiento y contrastar su idoneidad con la praxis. Pero también porque no se pueden dejar las cuestiones éticas al libre albedrío de los profesionales, si lo que se pretende es la cohesión profesional y la búsqueda de la excelencia. Esto no debe suponer ningún impedimento para fomentar el debate, más bien al contrario, pero coadyuva a que el debate esté basado en la realidad laboral.

Además del código deontológico, Vilar (2009) propone crear guías orientativas e interpretativas de referencia. Las guías orientativas son eminentemente deontológicas e inspiradas en principios y caen en el terreno de la autorregulación y libre adscripción. Por su parte, las guías imperativas son fundamentalmente jurídicas y se inspiran en la legalidad. Los reglamentos y protocolos serían normas imperativas, y las guías de buenas prácticas, orientativas.

Las normas son necesarias, representan el marco común en el que los profesionales pueden reconocerse y, por lo tanto, son imprescindibles para unificar la profesión. En el contexto educativo y de vulnerabilidad, las normas son indispensables para regular la relación con el otro y evitar prácticas abusivas. No obstante, tampoco es recomendable pecar de exceso. De hecho, en los códigos deontológicos se apunta hacia los principios generales para orientar las actuaciones, pero no son prontuarios. Hay que evitar situaciones en las que los protocolos y reglamentos se convierten en objetivos en sí mismos, con el riesgo de anquilosar la intervención, sustituyendo la primordial reflexión profesional por la dogmática aplicación de normas, y en la que la responsabilidad profesional sucumbe ante los sacralizados protocolos. Como señala Cortina (2013), un profesional que solo se dedica a cumplir normas cae en la burocratización que impide acceder a la excelencia profesional, entendida como ser el mejor en relación con algo, no solo para sacar provecho propio, sino para poner sus capacidades al servicio de la comunidad (Cortina, 2013, p. 111).

Por lo tanto, ante la imposibilidad de recoger toda la casuística de conflictos de valor a los que un profesional podrá enfrentarse al encuentro con el otro, este debe contar con la reflexión; una reflexión nutrida de la formación, de la experiencia y de la socialización profesional. Como señala Vilar (2009), 
los profesionales de la educación social no son filósofos, pero deben tener la imprescindible cultura ética que les permita realizar su trabajo con excelencia.

4. ¿Cómo influye la Ética PeRsonal EN LA ÉticA PROFESIONAL?

Para Cortina (s. f.), una de las características de las profesiones es que implican necesariamente un cierto grado de vocación que define como "contar con unas aptitudes determinadas para su ejercicio y con un peculiar interés por la meta que esa actividad concreta persigue" (p. 107). Parece razonable que, sin cierta sensibilidad hacia las personas o problemáticas con las que se trabaja, es difícil poder desempeñar una buena labor profesional y, de hecho, atribula imaginar a alguien que trabaje en el ámbito socioeducativo al margen de la compasión y la humanidad, de forma fría y mecánica. Es más, la compasión expresa la interdependencia humana y estimula las ansias de justicia (Camps, 2011, pp. 122-139).

Esta afirmación conduce inexorablemente a la idea de que un determinado carácter ético parece ser deseable para desempeñar adecuadamente esta profesión educativa y social. Las virtudes y los valores se asientan en sentimientos, pero se materializan en hábitos modificables que se adquieren con la práctica (Camps, 2013, p. 62), de ahí la importancia de la formación universitaria y la socialización profesional para difundir y adherirse a los valores y virtudes de la profesión.

Pero, como decíamos, si las profesiones tienen sentido en función de los objetivos legítimos a los que se comprometa esa actividad profesional, que justifican así su existencia, cuando una persona ingresa en la profesión, independientemente de los motivos que la llevaron a esta elección, debe asumir como propias las metas de la profesión (Cortina, 2013, p. 108). Por lo tanto, no se trataría de que el profesional aplicase en su ejercicio profesional sus principios éticos personales, sino que, de lo que se trata, es de que en su actividad profesional se apoye en los códigos éticos, virtudes y fines de la profesión, por las peculiaridades del contexto laboral.

Las decisiones que se toman como profesional se hacen bajo las siguientes condiciones: su función representativa y su carácter institucional (Cortina, s. f., p. 203). Es decir, aunque sea el profesional quien toma la decisión, esta 
función ha sido encomendada por la sociedad para que realice un determinado servicio. Al mismo tiempo, el profesional representa a la institución para la que trabaja. Por lo tanto, aunque los dilemas éticos siempre se presentan como una vivencia personal y subjetiva, un conflicto ético de carácter profesional no puede gestionarse en los mismos términos en los que se haría con un conflicto ético de carácter personal (Vilar, 2013, p. 31), porque como profesional se tienen que asumir responsabilidades hacia los usuarios, la entidad, los colegas, la profesión y la sociedad.

Al respecto, Cortina (s. f., p. 199) emplea la distinción de Weber entre la ética de las convicciones que, en términos kantianos, hace referencia a principios y valores que deben respetarse incondicionalmente, frente a la ética de la responsabilidad por las consecuencias. La primera estaría guiada por las intenciones y la segunda por los resultados. En la acción profesional las buenas intenciones, aunque son importantes, no garantizan buenos resultados per se, y cuando lo que está en juego es el bienestar y el futuro de una persona en situación de indefensión, el trabajo profesional debe medirse por los resultados. Por lo tanto, defiende que la ética de la responsabilidad por las consecuencias es la que debe guiar el ejercicio profesional. Para Camps (2013, p. 356), la ética de los principios y de las consecuencias no son opuestas, sino complementarias, y precisan de la mediación de la ética de las virtudes para materializarlas, porque ni los principios ni las consecuencias tienen incidencia si no van acompañadas de la buena disposición de los sujetos. Por ello es imprescindible cultivar las virtudes profesionales, tanto en la formación como en la socialización profesional.

Cortina (s. f., p. 196) considera que en la actualidad no hay concepciones morales inconmensurables y que lo más habitual en las sociedades posmodernas son tensiones y conflictos derivados de identidades y valores diversos, y que los conflictos de valor que puedan darse en un mismo sujeto en una situación laboral pueden resolverse con incoherencias en su sistema moral, porque las personas pueden adoptar más de un rol, ya que nada garantiza que los imperativos morales tengan que armonizar, y que la vida no puede convertirse en un sistema lógico total porque dificultaría dialogar y aprender entre las diversas Weltanschauungen, formas diferentes de ver el mundo. Asimismo, critica el utilitarismo moral, es decir, convertir en razón moral a cualquier argumento en 
función de la ventaja que racionalmente se pueda obtener con esta. Para Vilar (2013, p. 157), los problemas éticos profesionales se concretan en la toma de decisión entre distintas opciones con los siguientes elementos: el ético, técnico, institucional y personal, sobre los cuales se debe deliberar. Aquí emerge de nuevo una de las virtudes más importantes en el ámbito profesional: la prudencia aristotélica (Camps, 2013, p. 362), esto es, la aplicación de la reflexión en la práctica. Así pues, los profesionales de la educación social deben reflexionar en torno a los dilemas éticos, teniendo en cuenta el carácter público e institucional de su actividad, sin recurrir a su sistema privado de valores, pero sin ignorarlo porque influye en la toma de decisiones, guiándose por los fines legítimos de la profesión y materializándolos según las guías orientativas e imperativas existentes específicas del campo profesional (Vilar, 2013).

Por lo tanto, además de compasión hacia las personas con las que se trabaja, manteniendo el principio de distancia óptima (Baptista, 2005, p. 122), sin caer en los excesos de la frialdad ni el amor, sí que existen valores éticos inconmensurables: los límites son los derechos humanos, porque no es compatible ser educador social con consumir prostitución y pornografía, defender totalitarismos, mantener prejuicios racistas o defender prerrogativas de clase. Consideramos con escepticismo la posibilidad de que las grandes discrepancias entre la ética personal y profesional no acaben afectando al ejercicio profesional. Por eso, coincidimos con Martínez (2006) cuando señala la posibilidad de considerar la profesión como un proyecto ético personal y un compromiso de ciudadanía, porque parece difícil articular una separación radical entre ciudadanía y profesionalidad.

\section{Pluralidad de objetivos Que interpelan a la educación Social}

Uno de los dilemas éticos más frecuentes a los que tienen que hacer frente los profesionales es el de trabajar en pro de la justicia social en medio de un sistema neoliberal, que a menudo se materializa en situaciones de exclusión resultado de las brechas en el sistema de garantías y de derecho y en programas que ahondan en la exclusión social. 
A este respecto, Martínez (1995, p. 29, citado en Caride, 2002, p. 109) enumera los diferentes objetivos que se le demandan a la educación social y que la posicionan ante un rol contradictorio: objetivos eficientistas que imponen las estructuras burocráticas tendentes a destacar los logros; los objetivos de socialización para integrar a los sujetos; y los objetivos propios de la tarea educativa.

Ante las paradojas a las que tienen que enfrentarse los profesionales de la educación social, García y Sáez (2017) proponen la ética del agente doble, que consiste en el bricolaje práctico e intelectual recreado en prácticas que fomenten la integración. Es decir, "trabajan para un sistema y en un sistema, pero no son exactamente ese sistema: la Educación Social es una profesión mediadora entre los intereses y finalidades de las políticas sociales y las necesidades y deseos de los ciudadanos" (p. 108).

Para Cortina (2013, p. 109), no hay ambigüedad, señala que el compromiso de los profesionales debe ser con las "personas de carne y hueso" que son las que dan sentido a cualquier institución social, no con las burocracias.

Estas dos posturas confluyen en un aspecto importante: los profesionales de la educación social son representantes de la institución, pero no deben identificarse con las políticas públicas, volubles en función de quien las gestione y susceptibles de fomentar o no la justicia social, ni tampoco con la entidad para la que trabajan.

Sin embargo, la educación social no se rige por la lógica mercantil del cliente siempre tiene la razón. Así como existen lógicas institucionales que fomentan la exclusión, puede suceder que las demandas de los sujetos sean improcedentes, injustas o contraproducentes. Si tomamos parte inflexible por los sujetos, podríamos estar asumiendo una posición partidista. Si nos posicionamos siempre a favor de la institución, caeríamos en el ethos burocrático. Si abandonamos la ética a favor del sectarismo profesional, claudicaríamos ante el corporativismo.

La educación se juega, por lo tanto, entre la integración y la transformación, entre la ayuda y el control, y en la búsqueda de este equilibro la balanza deberá inclinarse hacia uno u otro lado. Por lo tanto, el eje sobre el que pivota la orientación es la ética profesional materializada en los objetivos profesionales legítimos. Para que los profesionales de la educación social puedan recrear estos objetivos, se requiere autonomía profesional y, en este sentido, es necesario 
que se asienten sobre unas buenas condiciones laborales para poder hacerla efectiva y en unas buenas virtudes profesionales.

El código deontológico debe servir para este fin y así aparece recogido en uno de sus objetivos: reforzar la autonomía de los profesionales con respecto a las políticas sociales, las instituciones, los mandatos y las exigencias y presiones sociales (ASEDES, 2007, p. 22). Se trata de una forma de lealtad institucional que no cae en el corporativismo, que fomenta la cooperación con la institución en la búsqueda conjunta de la justicia social.

Los profesores Sáez y G. Molina (2006, p. 347) señalan los elementos que hay que tener en cuenta para elaborar una ética aplicada a la educación social: la autonomía profesional, el nivel de competencia técnica, el cuadro de valores que el profesional pone en juego y una ética de la relación educativa.

Basándonos en la lista anterior, serían necesarias las siguientes condiciones:

- Un elevado grado de autonomía profesional para trabajar en pro de los objetivos legítimos, favorecida por unas buenas condiciones laborales para no claudicar ante el corporativismo ni la burocracia ni ante el clientelismo.

- Un buen nivel de competencia técnico pero enmarcado por una ética profesional en la que se desarrollen las virtudes profesionales. Entre estas, fomentar a profesionales reflexivos y críticos, porque no hay ética sin autonomía, para que su conciencia moral les permita aceptar libremente determinadas normas por el bien común.

- Un código deontológico con fines éticos, no corporativistas, difundido entre sus profesionales y de obligado cumplimiento y debate.

- La eticidad como profesional debe ser asumir los valores y fines de la profesión y no usar su registro moral personal para resolver conflictos de valor laborales. Debe tener vocación o sensibilidad hacia las personas con las que trabaja y asumir su compromiso profesional como una forma de ciudadanía.

- Ética de la relación educativa. El profesional debe confiar en la educabilidad del otro, cultivar las virtudes profesionales para materializar los principios éticos, entre ellas, ejercer el respeto mutuo basado en la dignidad de la persona por medio de actuaciones mediadas por el vínculo social a través de la autonomía y la participación. 


\section{6. ÉtICA DE LAS VIRTUDES: EL VALOR DEL RESPETO EN LOS PROFESIONALES}

Las tribus sudafricanas del Natal tienen un saludo muy hermoso, Sawubona, que significa: "Te veo. Eres importante para mí y te valoro". La respuesta a este saludo es Shikoba: "Entonces yo existo para ti".

Como este tradicional saludo africano indica, todas las personas necesitamos sentirnos reconocidas por el otro. Es común que personas en situaciones muy complicadas pidan con vehemencia ser tratadas con respeto, porque es la vivencia del desprecio lo que las lleva a buscar imperiosamente esa consideración. Mostrar respeto es un signo de mutuo reconocimiento, de ratificar la dignidad intrínseca de la que somos poseedores como personas y es la idea que fundamenta que todos los seres humanos tenemos derecho a acceder a una vida plena.

Bajo este marco se ampara el Estado de derecho y justicia, que considera que las necesidades básicas humanas son derechos de ciudadanía y, por lo tanto, un deber de Estado hacer efectivos estos derechos en términos de calidad. Sin embargo, la realidad es otra. Estas premisas no aseguran el respeto hacia los beneficiarios de las políticas sociales ni la valoración social hacia los más vulnerables en una sociedad tan desigual como la nuestra. Es necesario reflexionar sobre cómo articular un sistema en el que sea posible atender a la dependencia sin degradar a la persona, manteniendo su integridad.

Si, como dice Camps (2013), cultivar las virtudes de los agentes es la condición de posibilidad para materializar los principios éticos, vamos a centrarnos en la importancia del valor del respeto como mandato ético de los profesionales de la educación social.

La dimensión relacional es básica en las relaciones educativas (Vilar, 2013, p. 126), y así lo constatan algunas investigaciones en las que los destinatarios valoran principalmente el buen trato recibido por parte de los profesionales de la acción socioeducativa (Montserrat y Melendro, 2017).

Uno de los dilemas éticos que más nos preocupa es la falta de respeto hacia los sujetos de la acción por parte de los profesionales de la educación social. En este apartado solo vamos a tratar el tema del respeto en su relación con el vínculo profesional, aunque pensamos que el respeto y la falta de este hacia las personas más vulnerables tienen que ver con factores estructurales y su conexión directa con las lógicas neoliberales y la consecuente criminalización 
de los problemas sociales en un mundo cada vez más ausente de respeto mutuo (Camps, 2008, p. 83; Wild, 2006, p. 100).

Es bien sabido que a la educación social se le encomienda la atención de población vulnerable y vulnerada. En estas situaciones de fragilidad y máxima indefensión, es necesario estar alerta para que los profesionales, como representantes de lo social, no lleven a cabo conductas de dominación, entendidas como un tipo de control no legítimo de la población a la que atiende. Las personas que trabajan en el ámbito socioeducativo están familiarizadas con las humillaciones y el trato degradante que, desde determinadas instancias, son tratadas algunas personas y colectivos. Los profesionales de la educación social pueden estar incurriendo en prácticas similares alegando un hipotético beneficio superior para el sujeto basado en el supuesto conocimiento experto (traducido al lenguaje condescendiente del "yo sé lo que te conviene") o a la fiscalización burocrática y degradante del "esto es lo que hay". La influencia del paradigma tecnológico en el exceso de tecnificación en la educación social (García, 2003, p. 43) ha provocado que en muchas ocasiones se haya perdido la mirada política y que aparezca el despotismo técnico que conduce a la falta de empatía, a no aceptar críticas, al abuso de poder o al maltrato institucional (Vilar, 2013, p. 66).

El ensayo de Sennett Respeto (2003), una mezcla entre biografía y teoría social, da buena cuenta de algunas de las formas en las que se materializa esta falta de respeto desde las instituciones: la vergüenza que provoca la dependencia; las formas degradantes de la compasión como la caridad, porque está íntimamente ligada con la desigualdad de recursos y talentos, con la burocracia impersonal o el intrusismo, con la infantilización de las personas adultas pobres como espectadoras de su propia vida a expensas de las decisiones de los servicios públicos, que las transforman en meros consumidores de cuidados; y el trato de superioridad de los trabajadores sociales y su argot técnico degradante.

Para Sennett (2003, p. 4), la falta de respeto no consiste en insultar, más bien en "no ofrecerle reconocimiento, no se le ve como un ser humano integral cuya presencia importa". Camps (2008, pp. 83-90) apunta a otras dimensiones del respeto que ayudan a profundizar conceptualmente en él: es un valor relacionado con la autoridad, pero no contrario al afecto; va más allá de la mera tolerancia porque implica considerar a todo el mundo, incluidas las personas que nos resultan extrañas o incómodas; es complementario a los conceptos de 
reconocimiento y reciprocidad, especialmente en el caso de las personas más desiguales, y enseñar a respetar a los demás es un complemento del aprendizaje de la libertad.

Basándonos en esto, podríamos concretar la falta de respeto en lo que atañe a los profesionales en los siguientes aspectos: en la ausencia de reconocimiento del otro como interlocutor válido, en la superioridad del profesional que desemboca, cuando menos, en condescendencia o en ciertas prácticas intrusivas, y en la falta de expectativas positivas en el sujeto, en la desconfianza en las posibilidades de poder ser de ese otro.

En el ensayo de Sennett (2003), encontramos varias pistas para pensar el tema del respeto desde los servicios sociales y educativos, analizado desde la relación que mantiene con la desigualdad.

El sociólogo constata que hay diferencias entre respetarse uno mismo y ser respetado por los demás. Una de las causas de esta falta de respeto es la desigualdad de talento. Ser dependiente de la atención social provoca humillación. Para ganar el respeto no hay que ser débil, no hay que tener necesidad de otros, lo que conduce a la idea del equilibro en el intercambio social.

En este sentido, Cortina (2017, p. 123) señala que el rechazo de los pobres se fundamenta precisamente en que, en el mundo del intercambio, son los que parece que no tienen nada que ofrecer a cambio de la ayuda recibida. Sin embargo, las tesis de Mauss (2009) van en otra dirección, señalan que son precisamente los desequilibrios en los intercambios, la asimetría, la que desencadena el vínculo social. En los intercambios igualitarios capitalistas (alguien vende equis y otro paga la cantidad económica equivalente), no se crea ningún vínculo emocional.

Con estas mimbres, trasladando la discusión a los servicios públicos, el fondo de la cuestión es cómo articular el respeto en una situación de dependencia objetiva, que genera humillación, para que dé lugar a un vínculo social positivo y cómo hacer para que las desigualdades no se interpongan en el respeto mutuo en las relaciones entre los sujetos y los profesionales, las instituciones y la sociedad.

Sennett (2003, p. 206) considera que los códigos sociales de producción de respeto están asociados, además de los mencionados cuidar de sí y hacer algo por uno mismo, también al factor de ayudar a los demás, o al giro hacia afuera, como él lo denomina. En este punto confluye con el pensamiento de Cortina, 
en la necesidad de que las personas que se benefician de una ayuda den algo a cambio, para disfrutar del respeto de los demás, porque si no se pide nada por ello significa que tampoco se reconoce al otro como interlocutor válido, que no se deposita confianza en sus posibilidades y habilidades.

Con todo, el hecho de que sea diferente el respeto hacia uno mismo y ser respetado no significa que no estén interconectados, porque las personas también lo están. Por lo tanto, ofrecer reconocimiento al otro, legitimarlo como interlocutor válido, puede dar lugar a mejorar el respeto que tiene de sí mismo, porque se deposita confianza en sus habilidades. Así pues, ante la dependencia institucional y frente al rol asignado de espectador impertérrito de su propia vida ante decisiones heterónomas, hay que introducir el elemento autonomía; frente a la pasividad hay que dar lugar a la participación.

A este respecto, la postura de Núñez (2010) es muy clarificadora sobre cómo ha de ser la participación, cuando distingue entre tomar parte y ser parte, entendiendo la participación real y efectiva no como una dádiva institucional, sino como un derecho del sujeto. Como señala Núñez (2010, p. 110): “El lugar que se le asigna al sujeto lo define socialmente. Si el lugar cambia, cambian las propiedades, en tanto que son aferentes al lugar. Las propiedades no son inherentes al sujeto, como se atribuye desde el presupuesto que confiere a tal sujeto estatuto ontológico".

De esta forma, considerar al sujeto de la acción desde estas coordenadas significa ofrecerle un lugar nuevo, donde su valoración no se construya en términos deficitarios o carenciales, sino que se considera como un interlocutor válido para participar en las condiciones de su dependencia. De esta forma, su participación desde la autonomía produce la conexión y el vínculo, un nosotros, pero manteniendo la intimidad y la dignidad, condición sine qua non para que se produzca respeto y vínculo.

En cuanto al profesional y su profesionalidad, en la valoración del sujeto ha de tener en cuenta lo que señala el pedagogo alemán Thiersch $(2017$, p. 16): “¡olvida que soy discapacitado, pero no olvides que soy discapacitado!”, que interpretamos de la siguiente forma: no te concentres en mis carencias, ni me definas por ellas; no las uses como coartada para no verme globalmente, pero tenlas presente porque esas carencias dificultan el acceso a mi bienestar, a la satisfacción de mis necesidades básicas, y por ello necesito apoyo. Y ahí entra en juego la ética profesional. 
Aplicarla entraña gran dificultad porque la realidad es que la población vulnerable tiene graves dificultades para ejercer su autonomía. Los profesionales se mueven en un territorio fronterizo: mantener el difícil equilibrio entre el respeto a los sujetos de la acción y conseguir los objetivos de cambio o transformación. Y es que, como apunta Baptista (2005, p. 146), es la intencionalidad educativa la que compromete a la ética. Para que la acción profesional sea legítima, es necesario equilibrar los objetivos educativos de transformación o socialización, con la autonomía y libertad del sujeto que hay que educar.

Conforman las teselas de este mosaico socioeducativo la autoridad profesional y las formas de dominación vinculadas al ejercicio de poder (Vilar, 2013, p. 67) que le otorga su posición y conocimientos; los objetivos institucionales y sociales, que demandan unos determinados resultados y establecen fronteras; y la libertad de los sujetos en situación de dependencia. Para evitar excesos deben entrar en juego los límites. La confianza en la educabilidad del sujeto no justifica el autoritarismo o el adoctrinamiento. Pero los límites también son necesarios para no caer en los riesgos de la asimilación con el usuario. Sobre este aspecto parece interesante la propuesta de Wild (2006, p. 97). Ante la imposibilidad de asumir todas las demandas de los sujetos, sugiere que hay que mantener el respeto a los procesos vitales. Todas las personas pasan por etapas y están sometidas a procesos de cambio. Por lo tanto, se hace necesario aclarar cuáles son los procesos vitales en juego de cada individuo en su situación particular y articular una relación entre la comprensión y la necesidad de cambio. Así pues, como profesionales educativos, el respeto debe aplicarse no solo a los fines, sino también a los medios, y solo se pueden imponer por el diálogo, por los contenidos educativos, aquellos valores u objetivos que consideremos universalizables.

El profesor García (2003, p. 98) apunta a que la ética del don en educación tiene que ser distinta a la de la lógica económica, la de dar para recibir. Entendiendo la educación social como el ejercicio de transmisión de los bienes culturales, se sitúa en la misma línea de pensamiento que el don, y propone unir tiempo con don. Con el don no solamente se da la cosa dada, sino que lo que se da es tiempo, para que quien lo recibe pueda hacerse cargo, porque es el tiempo el que permitirá la (trans)formación del sujeto. Pero en el caso de la cultura el educador/a da lo que no le pertenece y dándola tampoco la pierde. 
La lógica de la educación se juega en la lógica del don (p. 101): “damos porque con anterioridad recibimos, porque establecimos una deuda simbólica al no poder devolver lo que recibimos. La intención apunta al dar más que a la esperanza de recibir".

La asistencia social en muchas ocasiones no se caracteriza por fomentar precisamente la autonomía, sino más bien la dependencia. Además de que las políticas sociales deben ser eficaces y, por lo tanto, transitorias, durante su aplicación ha de garantizarse el respeto, porque en el Estado de derecho y justicia social las personas no deben medirse ni por lo que valen ni por su utilidad, son un fin en sí mismas. Y esta posición ética debe ser cardinal para los profesionales de la educación social.

\section{BiBLIOGRAFÍA}

Amorós, C. (1991). Hacia una crítica de la razón patriarcal. Barcelona: Anthropos.

ASEDES (2007). Documentos profesionalizadores. Toledo: Asociación Estatal de Educación Social.

Baptista, I. (2005). Dar rostro ao Futuro: A educaçao como compromisso ético. Oporto: Prediços.

Bourdieu, P. (2006). Razones prácticas (Sobre la teoría de la acción). Barcelona: Anagrama.

Cabanas, E. y González-Lamas, J. (2021). Felicidad y educación: déficits científicos y sesgos ideológicos de la "educación positiva". Teoría de la Educación. Revista Interuniversitaria 33(2), 65-85. DOI; ORG/10.14201/ TERI. 25433

CAmps, V. (2013). Breve historia de la ética. Barcelona: RBA.

CAmps, V. (2011). El gobierno de las emociones. Barcelona: Herder.

CAmps, V. (2008). Creure en l'educación: L'assignatura pendent. Barcelona: Ediciones 62.

Caride, J., Sanjurjo, L. y Trillo, F. (2017). Maestros y educadores en el espacio común de las profesiones y la educación superior. Revista Interuniversitaria de Formación del Profesorado 89, 89-101. 
CARide, J. (2002). Construir la profesión: la Educación Social como proyecto ético y tarea cívica. Pedagogía Social. Revista interuniversitaria (9), 91125.

Cortina, A. (2017). Aporofobia, el rechazo al pobre: un desafio para la democracia. Barcelona: Paidós.

Cortina, A. (2013). ¿Para qué sirve realmente la ética? España: Paidós.

Cortina, A. (1993). Ética discursiva y democracia política. Revista Colombiana de Psicología (2), 107-116.

Cortina, A. (s. f.). Ética de las profesiones y de la función pública. Recuperado de: https://archivos.juridicas.unam.mx/www/bjv/libros/5/2228/9.pdf

ECCLeston, K. (2004). Learning or therapy? The demoralisation of education. British Journal of Educational Studies 52(2), 112-137.

García, J. (2003). Dar (la) palabra: deseo, don y ética en educación social. España: Gedisa.

GarcíA, J. y SÁEz, J. (2017). Investigadores, docentes y educadores frente a la exclusión social: Paradojas y apuestas. Educación XX1 20(2), 95-112.

DOI: https://doi.org/10.5944/educxx1.19033

Laval, C. (2005). Per què l'escola no és una empresa. Barcelona: UOC.

Martínez, E. (2006). Ética de la profesión: proyecto personal y compromiso de ciudadanía. Veritas I(14), 121-139.

Mauss, M. (2009). Ensayo sobre el don. Forma y función del intercambio en las sociedades arcaicas. Buenos Aires: Katz.

Montserrat, C. y Melendro, M. (2017). ¿Qué habilidades y competencias se valoran de los profesionales que trabajan con adolescencia en riesgo de exclusión social? Análisis desde la acción socioeducativa. Educación XX1 20(2), 113-135. DOI: https://doi.org/10.5944/educxx1.19034

NúÑEz, V. (2010) (coord.). Encrucijadas de la educación social. Orientaciones, modelos y prácticas. Barcelona: UOC

NúÑEZ, V. (2003). Entre la tecnociencia y el tecnopoder: el desafío de mantener abierta la pregunta acerca de las condiciones de producción de la Pedagogía Social. Pedagogía Social. Revista interuniversitaria (10), 11-122.

NúÑEZ, V. (1999). Pedagogía social: cartas para navegar en el nuevo milenio. Buenos Aires: Santillana.

Pantoja, L. (2012). Deontología y código deontológico del educador social. Pedagogía Social. Revista Interuniversitaria 19, 65-79. 
PARRenoud, P. (2008). La construcción del éxito y del fracaso escolar. Madrid: Morata.

PÉRez, A.I. (2000). La cultura escolar en la sociedad neoliberal. Madrid: Morata.

Prieto, M. (2018). La psicologización de la educación: Implicaciones pedagógicas de la inteligencia emocional y la psicología positiva. Educación XX1 21(1), 303-320. DOI: https://doi.org/10.5944/educxx1.20200

SÁEz, J. (1994). El educador social. Murcia: Universidad.

SÁez, J. y García, J. (2006). Pedagogía social: Pensar la Educación Social como profesión. Madrid: Alianza.

Sennett, R. (2003). El respeto. Barcelona: Anagrama.

SolÉ, J. y Moyano, S. (2017). La colonización Psi del discurso educativo. Foro de Educación 15(23), 101-120. DOI: dx.doi.org/10.14516/fde.551

Tiersch, H. (2017). Das Konzept Lebensweltorientierte Soziale Arbeit, skizziert. Recuperado de: https://www.hans-thiersch.de/Hans-Thiersch.de/Willkommen.html

VALCÁRCEL, A. (2002). Ética para un mundo global: una apuesta por el humanismo frente al fanatismo. Barcelona: Temas de Hoy.

VILAR, J. (2009). La ética en la práctica cotidiana del ejercicio profesional. RES: Revista de Educación Social 10.

VIlar, J. (2013). Cuestiones éticas en la educación social. Barcelona: UOC.

WILD, R. (2006). Libertad y límites, amor y respeto: lo que niños necesitan de nosotros. Barcelona: Herder. 